\title{
Megaprojects, Complexity, and Investment Decisions
}

\author{
Uyiosa Omoregie \\ Brass LNG, Lagos, Nigeria \\ Email: uyiosaomoregie@yahoo.co.uk
}

Received 21 March 2016; accepted 12 April 2016; published 15 April 2016

Copyright (C) 2016 by authors and Scientific Research Publishing Inc.

This work is licensed under the Creative Commons Attribution International License (CC BY). http://creativecommons.org/licenses/by/4.0/

c) (7) Open Access

\begin{abstract}
The need for basic infrastructure for economic development in developing countries has made megaprojects popular, in such parts of the world. Megaprojects can be very important to a host country: the Nigeria Liquefied Natural Gas (NLNG) Project has contributed about four percent of Nigeria's Gross Domestic Product. However, due to the complexity involved with megaprojects, project failure rate is high around the world, especially so for upstream oil and gas projects. This paper recommends a systems approach to megaprojects analysis, for a better understanding of these projects: from the pre-final investment decision (FID) stage through project execution. This author believes that a system approach to megaprojects analysis should provide better decision quality for decision makers.
\end{abstract}

\section{Keywords}

Megaprojects, Complexity, Investment, Decision Analysis

\section{Introduction}

Megaprojects are defined in this paper as large industrial projects with capital costs of $\$ 1$ billion or more, following Merrow [1]. The need for basic infrastructure for economic development in developing countries has made megaprojects popular, in such parts of the world. Megaprojects can be very important to the host country: the Nigeria Liquefied Natural Gas (NLNG) Project has contributed about four percent of Nigeria's Gross Domestic Product (GDP) [2].

Megaprojects have been executed for thousands of years: The Great Wall of China and the Pyramids of Egypt are two famous examples. A more modern famous example of a megaproject is the U.S. National Aeronautics and Space Administration (NASA) project that, in 1969, successfully puts a man on the moon. 
The decade 2000-2010 produced more large and complex projects than any other comparable period in history [3]. The period of low oil prices in the 1970s and 1980s witnessed relatively few megaprojects. Most of the megaprojects in the 1980s that reached the planning stage were terminated as commodity prices fell in that decade. The industrialization of China and India, with the increased demand for commodities, within the context of global economic growth, created more demand for megaprojects. To satisfy the increasing demand for such commodities as crude oil, international oil and gas companies (IOCs) were given access to difficult terrain in Brazil, Venezuela, the Capsian and Russia. In such difficult terrain, IOCs differentiated themselves from national oil companies (NOCs), with their technical expertise, as a larger portion of easily accessible exploitable natural resources were held by NOCs.

As projects increase in size, and become more complex, managing these projects becomes more challenging. Schedule slippage and cost overruns are familiar occurrences in megaprojects. Merrow [1] discovered that the most important correlate of cost growth and schedule slippage for industrial megaprojects were caused by the interface challenges between the projects and the host governments. Challenges imposed by host governments include: health, safety and environmental (HSE) regulations, labour laws and opposition, procurement and local content restrictions. From a project economics point of view, megaprojects frequently end up with a negative net present value (NPV). Because of the large capital expenditure involved in these projects, investment decisions usually take longer, and require more thorough analysis.

Oil and gas megaprojects have been found to have poor project execution record, in recent years [4]. Upstream oil and gas megaprojects, particularly, perform poorly compared to midstream and downstream megaprojects. The yardstick for success defined by how well these projects perform, compared with expectations when final investment decisions (FID) were taken [4]. It was found that project failure was positively correlated with project size. Oil and gas megaprojects usually created schedule targets that were too optimistic, and often missed. One reason for the poor performance of these megaprojects could be their complex nature. The management of complex systems, like megaprojects, required a shift in perspective.

This paper begins by describing complex systems, distinguishing complex systems from complicated systems. Next, a particular approach to managing complexity is presented: the systems approach. An example of a complex system, an oil and gas megaproject, is presented. Finally, the importance of decision quality for megaprojects, especially for final investment decisions (FID) is highlighted.

\section{Managing Complexity}

Simon [5] defined complexity as a system made up of a large number of parts that interact in a non-simple way. Complex systems are composed of many interacting parts. The collective behavior of the different parts of a complex system, called "emergent" behaviours, can be difficult to understand. These emergent behaviours are together more than the sum of their individual parts [6]. All studies of complexity involve understanding systems with multiple elements adapting or reacting to the pattern these elements create [7].

\subsection{Complexity versus Complicated}

Complexity should not be confused with "complicated". INCOSE [8] separates complicated systems from complex systems. A complicated system should be broken down to its constituent parts, for better understanding. An example of a complicated system like an automobile, consists of fixed relationships between the constituent parts. Relationships in a complicated system can be reasonably predicted. Complex systems like ecological systems, a country's economic system, or megaprojects, cannot be understood in the same way. Emergent properties of complex systems disappear when we try to break them apart, to understand them [8]. Wolfram [9] describes the need for a fundamentally different approach, other than the reductionist approach, which has proved successful for non-complex systems.

"In the existing sciences much of the emphasis over the past century or so has been on breaking systems down to find their underlying parts, then trying to analyze these parts in as much detail as possible. And particularly in physics this approach has been sufficiently successful that the basic components of everyday systems are now completely known. But just how these components act together to produce even some of the most obvious features of the overall behavior we see has in the past remained an almost complete mystery".

The reductionist approach tends to rely on linear relationships or perspectives, whereas the systems perspective is circular, with multiple feedbacks (Figure 1). 

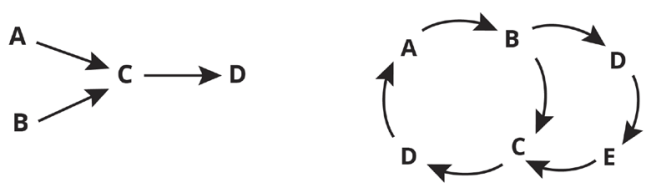

Figure 1. Linear perspective (left) versus systems perspective (right).

\subsection{Systems Approach}

The ancient philosopher Aristotle argued that true knowledge is gained when the whole is considered, rather than the constituent parts [10]. A systems approach, contrasts with a reductionist approach by using methods that rely on contextualizing to identify patterns of organized complexity. Systems thinking, for solving complex problems and managing complex situations, involves discovery, continuous learning, modelling and sensing-a unique perspective. One systems variable can be both a cause and an effect; this circular causation is constantly in the minds of system thinkers. Systems thinkers have been found to have the following perspective [11]:

- Seek to understand the big picture

- Observe how elements within the system change over time, generating patterns and trends

- Recognize that a systems' structure (elements and interactions) generates behavior

- Identify the circular nature of complex cause-and-effect relationships

- Surface and test assumptions

- Change perspective to increase understanding

- Consider an issue fully and resist the urge to come to a quick conclusion

- Consider how mental models affect current reality and the future

- Use understanding of system structure to identify possible leverage actions

- Find where unintended consequences emerge

- Recognize the impact of time delays when exploring cause-and-effect relationships

- Check results and change actions if needed: "successive approximation"

According to Senge [12], the systems approach to complexity looks for the causality that underlies the longer-term patterns of change in complex systems. This approach assumes that there are underlying interrelationships at deeper levels in systems, once understood, there will be a unique ability to influence change. Although these deeper levels in systems cannot be understood completely, plateaus of insight can be reached. Figure 2 illustrates the relationship between systems theory, systems perspectives and systems thinking. Systems thinking is an approach: it is an umbrella concept that covers both the specialized knowledge area of systems theory and the more generally applicable systems perspectives.

\section{Investment Decisions}

In a surprise announcement on 28 September 2015, the international oil company, shell, prematurely terminated its megaproject in the Alaskan Arctic [13]. It was reported that the megaproject had cost Shell about $\$ 7$ billion of investment and nine years of activity [14]. Such investment decisions for megaprojects are not easy to make. One thing that can be said about Shell's decision, is that the decision-makers involved were able to overcome what economists call the "sunk cost fallacy".

\subsection{Sunk Costs Fallacy}

When making investment decisions, economic theory prescribes that only incremental costs and benefits should affect decisions [15]. This means that historical costs should be irrelevant, during investment decision analysis. In practice, this message can be difficult to pass along to non-economists, during project analysis. The "sunk cost effect" occurs when there's the tendency to continue an endeavor once investment in money, effort or time has been made [16]. This type of behavior has been described by economists as "irrational" and the sunk costs effect has been called the "sunk cost fallacy". Arkes and Blumer [16] call the sunk cost effect "a robust judgement error". Although, large investments poured into a megaproject, will be difficult to ignore, money spent has been spent. All sunk costs are historical costs: bygones are bygones. Investment decision analysis is always forward-looking, it is about the profitability of future investments not past investments. The key to capital budgeting is measuring how future after-tax cash flows would change as a result of taking on a prospective project [17]. 


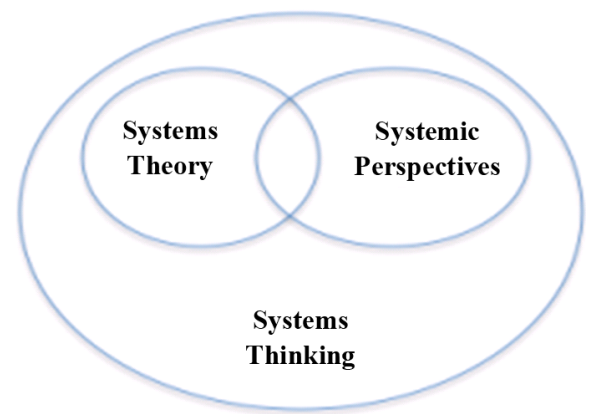

Figure 2. The relationship between systems theory, systems perspectives and systems thinking.

Sunk costs associated with the project should be ignored, as one of the implications of incremental analysis. These past costs will have no effect on the future cashflows of the project (regardless of whether the project is undertaken or not), because such costs have already been paid (or an obligation to pay has occurred).

\subsection{Influence Diagram}

The 'father' of decision analysis, Ronald Howard, stated that the real promise of decision analysis lies in its ability to provide a logical basis of decision making in the face of uncertainty [18]. Howard [19] went on to describe the "influence diagram" as "the greatest advance I have seen in the communication, elicitation, and detailed representation of human knowledge". A simple influence diagram for an oil and gas megaproject is shown in Figure 3.

\subsection{Decision Support Package (DSP)}

The decision support package (DSP) is described, by the Society of Petroleum Engineers (SPE) [20] as the primary instrument used by multi-company decision boards, in the oil and gas industry. The DSP makes a recommendation from alternatives available, and explains why the preferred alternative was selected. The DSP also summarizes all the work leading to the decision. The SPE recommends that the DSP should fulfill six elements of Decision Quality (DQ):

- Develop a relevant frame (are we solving the right problem?)

- Generate creative and doable alternatives (do we have a good set of alternatives?)

- Use relevant and reliable information (are the inputs into the analysis representative?)

- Assess the consequences of choosing different alternatives (what are the implications from the trade-offs being weighed?)

- Apply logical analysis (is the analysis approach reasonable?)

- Commit to action (are all participants ready to execute the decision taken?)

\subsection{Final Investment Decisions (FID)}

It was reported that, since the oil price collapse of 2014, 68 major oil and gas projects containing 27 billion barrels of oil equivalent (BOE), have had their final investment decision (FID) deferred. Capital expenditure of about $\$ 380$ billion has been deferred [21]. FID has been postponed for a minimum of 12 months, most projects have been pushed over to 2017 and beyond. There has been corporate pressure to free-up capital and reduce future spend. More investment/output will be pushed back further if oil prices do not recover. Deepwater projects have been affected the most.

\section{Conclusion}

Industrial megaprojects are important vehicles for foreign direct investment (FDI), especially in developing countries. The increase in megaprojects in the oil and gas industry, in the first decade of the $21^{\text {st }}$ century, exposed the challenges related to the management of these projects. Due to the complexity involved in megaprojects, a shift away from a linear (reductionist) perspective to a systems perspective is required. The systems 


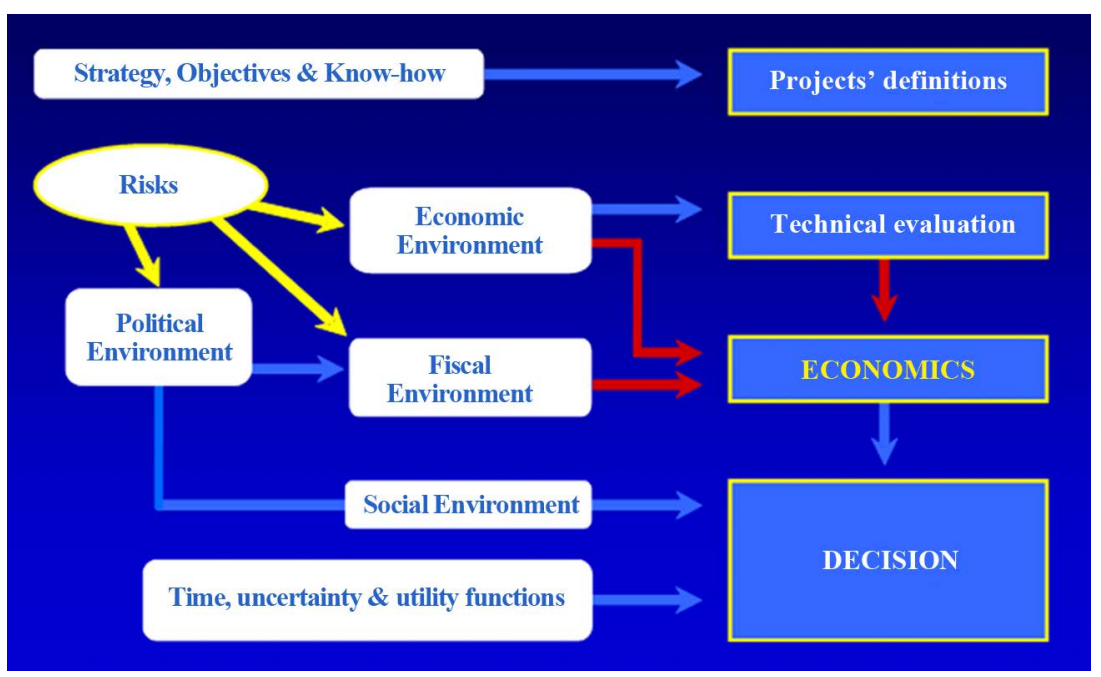

Figure 3. Asimple oil and gas megaproject decision influence diagram.

approach to megaprojects analysis is recommended in this paper, for a better understanding of these projects from the pre-FID stage through project execution. This author believes that a systems approach to megaprojects analysis should provide better decision quality for decision makers.

\section{References}

[1] Merrow, E. (1988) Understanding the Outcomes of Megaprojects. The Rand Corporation, Santa Monica.

[2] Nigeria LNG Limited (2015) NLNG and the Nigerian Economy. http://www.nlng.com/Our-Company/Pages/NLNG-and-the-Nigerian-Economy.aspx

[3] Merrow, E. (2011) Industrial Megaprojects. John Wiley \& Sons, Inc., Hoboken.

[4] Merrow, E. (2012) Oil and Gas Megaprojects: Our Recent Track Record. Oil and Gas Facilities, 1, 38-42. http://dx.doi.org/10.2118/153695-PA

[5] Simon, H. (1962) The Architecture of Complexity. Facets of Systems Science, 7, 457-476.

[6] Newman, M. (2011) Complex Systems: A Survey. http://arxiv.org/abs/1112.1440

[7] Arthur, W. (1999) Complexity and the Economy. Science, 284, 107-109. http://dx.doi.org/10.1126/science.284.5411.107

[8] INCOSE (2015) Systems Engineering Handbook: A Guide for Systems Life Cycle Processes and Activities. 4th Edition, John Wiley \& Sons, I., Hoboken.

[9] Wolfram, S. (2002) A New Kind of Science. Wolfram Media, Inc., Illinois.

[10] Stanford Encyclopedia of Philosophy (2002) Aristotle’s Metaphysics. http://plato.stanford.edu/entries/aristotle-metaphysics/

[11] Waters Foundation (2016) Habits of a Systems Thinker. http://watersfoundation.org/systems-thinking/habits-of-a-systems-thinker/

[12] Senge, P. (2016) Systems Thinking. Society for Organizational Learning, North America. https://www.solonline.org/?page=SystemsThinking

[13] Shell (2015) Shell Updates on Alaska Exploration. http://www.shell.com/media/news-and-media-releases/2015/shell-updates-on-alaska-exploration.html

[14] BBC (2015) Shell Stops Artic Activity over “Disappointing” Tests. http://www.bbc.co.uk/news/business-34377434

[15] Thaler, R. (1980) Toward a Positive Theory of Consumer Choice. Journal of Economic Behavior and Organization, 1, 39-60. http://dx.doi.org/10.1016/0167-2681(80)90051-7

[16] Arkes, H. and Blumer, C. (1985) The Psychology of Sunk Cost. Organizational Behavior and Human Decision Process, 35, 124-140. http://dx.doi.org/10.1016/0749-5978(85)90049-4

[17] Rich, S. and Rose, J. (1995) Capital Budgeting, Sunk Costs, and the Value of the Firm: A Pedagogical Note. Journal of Financial Education, 21, 52-54. http://www.jstor.org/stable/41948185 
[18] Howard, R. (1966) Decision Analysis: Applied Decision Theory. http://www.sdg.com/publications/decision-analysis-applied-decision-theory/

[19] Howard, R. (1988) Decision Analysis: Practice and Promise. Management Science, 34, 679-965. http://dx.doi.org/10.1287/mnsc.34.6.679

[20] Society for Petroleum Engineers (2016) SPE Technical Report: Guidance for Decision Quality for Multi-Company Upstream Projects. https://www.onepetro.org/general/SPE-181246-TR

[21] Wood Mackenzie (2016) Pre-FID 2016: US\$380bn of Capex Deferred. http://www.woodmac.com/analysis/PreFID-2016-USD380bn-capex-deferred? 